\title{
Leveraging Team Expertise Location Awareness in Improving Team Improvisation: A Dynamic Knowledge Integration Perspective
}

\author{
Suyang Ye' \\ Min Chen ${ }^{2}$ \\ 'School of Business Administration, \\ Zhejiang Gongshang University, \\ Hangzhou, People's Republic of China; \\ ${ }^{2}$ School of Business, Wenzhou University, \\ Wenzhou, People's Republic of China
}

Purpose: The uncertainties in the market have led to an increasing number of uncertainties and unexpected situations in the work environment of organizations. Based on information processing theory, we investigate how teams can dynamically integrate the expertise of their members to better respond to an uncertain market environment. We propose an important team cognition: team expertise location awareness and point out its unique impact on knowledge integration and thus on improvisation capabilities. In addition, we argue that shared leadership facilitates the use of team recognition resources by teams.

Methods: This study adopts a multi-source design approach and collects data from an information technology (IT) company that provides apps of voice socialization and game for foreign markets in southern China. Our sample comprised 86 IT teams, and hierarchical regression and bootstrapping methods are also employed to test the hypotheses.

Results: This study reveals that (1) team's expertise location awareness positively influences the team's knowledge integration ability which in turn enhances the team's improvisational ability; (2) team's knowledge integration mediates the effect of team's expertise location awareness and team's improvisational ability; (3) shared leadership moderated this above mediation effect.

Conclusion: In this paper, we introduce information processing theory into team improvisation research to understand why some teams can effectively utilize and integrate their members' knowledge and information and further contribute to effective team improvisation. These results' theoretical and practical implications for team expertise location awareness, team knowledge integration, shared leadership, and team improvisation are discussed.

Keywords: team expertise location awareness, shared leadership, team knowledge integration, team improvisation

\section{Introduction}

Organizations increasingly operate in unpredictable, dynamic, and complex environments. When faced with unpredictable conditions and time constraints, traditional planning and execution models can be ineffective. ${ }^{1}$ Increasingly, organizations are thus turning to flexible team-based structures to promote organizational adaptability and innovation. ${ }^{2}$ In such an organizational environment, understanding organizational improvisation cannot be separated from the study of team improvisation because organizational outcomes are produced through the execution and operation of teams. ${ }^{3}$ Team improvisational capacity is the ability of a team to spontaneously respond to a problem or opportunity in a novel way. ${ }^{4}$ For team
Correspondence: Min Chen

Email xuancm@gmail.com 
having a reliable ability to improvise means that the team has developed some productive improvisational action routines. The improvisation routines are not specific preparations and plans for each unique situation, but rather the team can respond effectively in any situation that may arise unexpectedly. ${ }^{5}$

To better understand how teams cope with and even take advantage of opportunities in these uncertain and unpredictable environments, scholars have shifted their research perspective from the study of the outcomes of improvisation to the study of the formation of improvisation. ${ }^{4}$ Such as organizational memory, ${ }^{6}$ team expertise, ${ }^{7}$ real-time information (eg, Moorman \& Miner, 1998), resource availability, ${ }^{8}$ working experience, ${ }^{4}$ team cohesion. ${ }^{9}$ One observation is that past research has generally examined thus far has been focused on team resources, especially team knowledge resources, with the tacit assumption that team with more available knowledge resources should be better able to effective reactions to unexpected situations.

However, potential factors associated with team knowledge utilization have been severely under-studied, especially how team members coordinate knowledge inputs and combine them into team processes. This is surprising, because merely having relevant knowledge resources does not guarantee that the team is structured to take advantage of their knowledge resource (Aime et al, 2014). ${ }^{10}$ As Woolley et a ${ }^{11}$ pointed out, the effectiveness of a team reaction depends on the extent to which the team has and uses its full resources well. Indeed, a central challenge to team improvisation is that how teams fully integrate and utilize the unique knowledge resources of each team member based on different environmental conditions. ${ }^{4}$ We submit that even if a team has favorable team knowledge resources, it is unlikely to have effective team improvisation capability if the team can not integrate its knowledge.

Based on information processing theory, ${ }^{12}$ which refers that the better a team's information processing capabilities are, the better it can handle the uncertain situations it faces. In other words, by integrating the knowledge and perspectives of the team members, teams have greater information processing capabilities to deal with unexpected challenges. ${ }^{13}$ In this paper, we introduce information processing theory into team improvisation research to understand why some teams can effectively utilize and integrate their members' knowledge and information and further contribute to effective team improvisation.
To effectively integrate team members' expertise, teams must first aware the value of that expertise. ${ }^{14,15}$ Team expertise location is Members' meta knowledge of each other's areas of expertise. ${ }^{16}$ We propose that expertise location facilitates improvisation because it helps teams to quickly organize and collect knowledge resources that already exist within the team. ${ }^{17}$ Furthermore, the effectiveness of established and static interaction patterns decreases in terms of constructing improvisational competencies, because team members must continually adapt the interaction patterns based on the requirements of the dynamic environment. ${ }^{18}$ Thus, the present research examines shared leadership, which refers to the team phenomenon whereby leadership is performed collectively by multiple members of a task group, ${ }^{19}$ as an important moderator. We posit those teams with high-level shared leadership should be more effective in leveraging team expertise location into knowledge integration, which should strengthen the team improvisation capability. Therefore, our research answers an important question: how teams can fully integrate and leverage the knowledge of their members to develop effective team improvisation to cope with uncertain situations.

\section{Theory and Hypothesis Development} Team Expertise Location Awareness and
Team Knowledge Integration

Team expertise location awareness refers to teams that know how knowledge is distributed among its members. ${ }^{20}$ Knowing the area of expertise of other team members serves an important integrative and coordinative function in the teams. With the awareness of the position of each members' professional knowledge, the team can connect members with their actual abilities and achieve the effective matching of human-professional knowledgetask. $^{20}$ Research has also shown that teams that assign tasks based on team expertise location are more likely to realize the full potential of team members. ${ }^{21}$

These findings suggest that team expertise location awareness, might be a key premise for the integration of knowledge in the work team. Specifically, when team members are acutely aware of how the expertise of themselves and other members is distributed in the team, they are likely to have an accurate expectation of each member's performance, ${ }^{16}$ which leads to an agreement, either explicitly or implicitly, among team members about the assigned tasks and the roles they should assume with each 
other. In other words, team expertise location helps the team establish consistency in how members integrate together and contribute to each other, which leads to similar mental representations of team members in terms of "who should do what and when they did what" so that the team can effectively and quickly mobilize the right members to effectively improvise when faced with unexpected situations.

Research also shows that teams with expertise location awareness are more likely to achieve higher levels of knowledge integration. ${ }^{16,22}$ For example, using a sample of National Basketball Association (NBA) All-Stars, ${ }^{23}$ this study concludes that players with a better understanding of other players' skills were better able to understand and predict each other's playing behaviors and strategies; therefore, the team as a whole can better dynamically integrate their actions on the court. Kanawattanachai and Yoo, ${ }^{16}$ also find that a high level of team expertise location awareness is necessary for effective knowledge integration. In conclusion, team expertise location awareness helps team members develop predictability of performance related to expertise, ${ }^{24}$ which in turn helps team members integrate each other's knowledge resources effectively. Based on the above analysis, we expect a positive relationship between team expertise location awareness and team knowledge integration among team members.

Hypothesis 1: Team expertise location awareness is positively related to team knowledge integration.

\section{The Moderating Role of Shared Leadership}

Shared leadership refers to a team phenomenon in which team members are allowed to offer their leadership to others and to the team mission. ${ }^{25-27}$ Ideally, team members' expertise is expected to be fully utilized under the structure of shared leadership (Pearce \& Conger, 2002) ${ }^{28}$ because all or the majority of members are able to get opportunities to utilize their expertise. ${ }^{29}$ Through shared leadership, teams are more like to put true experts to take the leading roles. When team members identify who possesses the required skills for the fulfillment of work tasks, shared leadership may increase the likelihood that the right person is brought to the forefront. In other words, shared leadership provides opportunities for team members to influence team processes based on their true expertise and competencies; thus, the knowledge and information of team members can be more effectively integrated.
Conversely, when the team has a low level of shared leadership, even if team members have optimal expertise to solve the current situational demand, the lack of opportunity to assume informal leadership roles results in the team not being able to put the most appropriate members in the right position to solve the problem. This can cost the team more time and resources to solve the current problem faced by the team, which is not conducive to the efficiency of the team in solving problems. In addition, the hierarchical structure may have those who lack the expertise to mentor other members. Under inappropriate leadership management, even if the team has a high awareness of expertise location, it will not be able to fully utilize the expertise of each team member and thus not able to reap the potential benefits of members' expertise. Therefore, based on the above discussions, we propose the following hypothesis.

Hypothesis 2: Shared leadership moderates the relationship between team expertise location awareness and team knowledge integration, such that the relationship will be stronger for teams with high shared leadership than for teams with low shared leadership.

\section{The Relationship Between Team Knowledge Coordination and Team Improvisation}

We further shift the focus of scholarly concerns before emphasizing knowledge resources to the microfoundations of "using resources well": the ability to integrate knowledge. Team knowledge integration refers to developing a reliable team communication model about how each member relates to each other and makes contributions when facing a complex situation. ${ }^{30}$ Team knowledge integration enables teams to effectively acquire and cross-use a broader range of problem-solving perspectives, bringing more new ideas to work and promoting team innovation; at the same time, effective knowledge integration enables members to quickly and accurately get each other's expertise connected and facilitating the effective flow and exchange of knowledge. ${ }^{31}$ Thus, team knowledge integration can help teams improvise effectively in an unpredictable and ever-changing environment.

On the contrary, with low team knowledge integration, it is difficult for the team to generate an effective and clear recognition of labor division, not knowing how to coordinate the contributions and roles of each other, which reduces the team's ability to search for and integrate information when 
the team faces problems, and makes it difficult for the team to link key elements of tasks with each other; it not only brings down the effectiveness of the team's decision-making process but also reduces the team's knowledge integration ability and also slows down the team's response speed. Thus, we propose hypothesis as follows:

Hypothesis 3: Team knowledge integration is positively correlated with team improvisation.

\section{The Mediating Role of Team Knowledge Integration in the Moderation Effect}

So far, this paper has proposed that team expertise location awareness positively affects team knowledge integration (hypothesis 1), shared leadership moderates the relationship between team expertise location awareness and team knowledge integration (hypothesis 2), and team knowledge integration positively affects team improvisation (hypothesis 3 ). Based on the above hypotheses, we expect team knowledge integration to mediate the moderating effect of expertise location awareness and shared leadership on team improvisation. Specifically, team expertise location awareness can effectively enhance team improvisation. When the team has a higher expertise location awareness, the team is more likely to identify members who are truly capable of solving the current situational demand. Combine with shared leadership, which enables the expertise and unique information of relevant members to be more effectively integrated for facilitating the team's ability to cope with complex situations. Team knowledge integration helps team to effectively utilize the existing human resources and knowledge pool within the team when facing unexpected situations, increases the team's response speed and effectiveness, see Figure 1. Therefore, we propose the following moderated mediation hypothesis.
Hypothesis 4: Shared leadership moderates the indirect effect of team expertise location awareness on improvisation through dynamic knowledge integration; this positive indirect effect is enhanced when shared leadership is high.

\section{Method}

\section{Sample and Procedure}

Participants were information technology (IT) professionals working at the technology-based technology company that provides apps of voice socialization and game for foreign markets in southern China. The characteristics of this company revealed by our preliminary interviews prove it well suited to test the conceptual model proposed by this research. First, this company set teams as the basic form to organize employees to participate in its various software development projects. The work of employees in these teams is highly interdependent, which requires the teams to integrate knowledge on different areas of expertise. It makes the integration of knowledge in the team a key factor for team effectiveness. Second, the R\&D team works with a large number of uncertainties as there is no existing script to follow during the project development process. At the same time, the high demand for stability in APP operation often requires the team to respond innovatively and timely to sudden or unexpected situations, which provides a well-suited environment for studying team improvisation. Finally, these teams involved in software development are mostly self-managed teams, which means that team members usually have many opportunities to participate in the decision-making process and assume leadership roles, allowing this paper to capture the impact of shared leadership.

To reduce common method bias, we use a multi-source design form of data collection ${ }^{31}$ with data collected from both employees and their supervisors. The survey was supported by the company's executives, and the HR manager

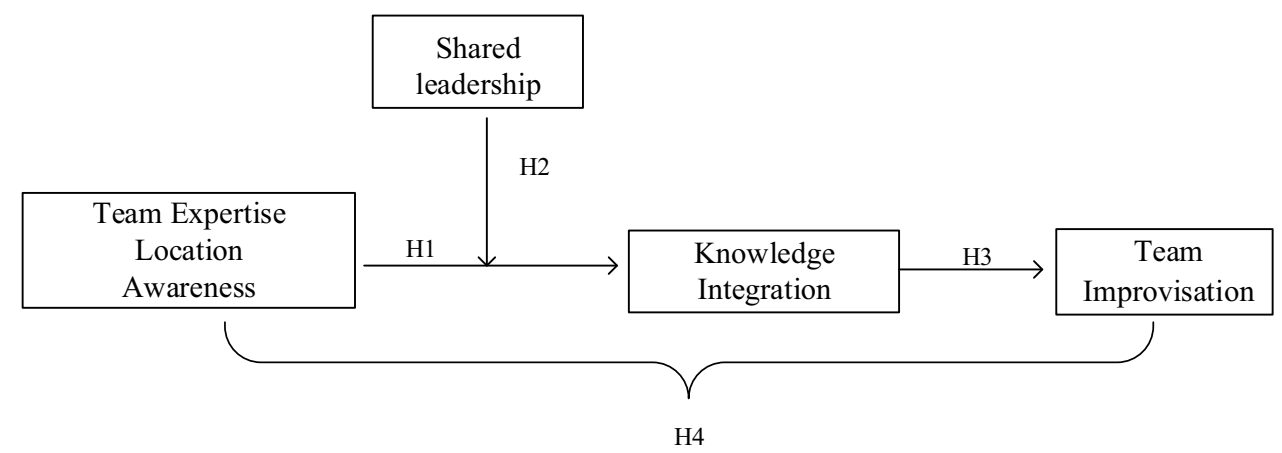

Figure I The conceptual model. $\mathrm{H}=$ hypothesis. 
provided a roster of surveyed employees and their leaders for this study. A total of two rounds of data were collected for this study, with a 2-month interval between the two rounds of the survey. Each employee and his or her leader were surveyed via a sealed paper questionnaire. For each team studied, the company's human resources manager provided the investigator with a list of team members. For the first-round survey, we measured the demographic variable, the independent variable of team expertise location awareness, and the moderating variable of team shared leadership. The secondround data were collected two months after the first round was done. In the second-round survey, team members assessed team knowledge integration, meanwhile, team managers assessed team improvisation.

A total of 527 questionnaires were returned in the firstround survey, with 503 valid questionnaires (95.44\% effective rate). After two months, team members evaluated the team's knowledge integration, while at the same time, leaders evaluated their team's improvisation. A total of 482 questionnaires $(95.56 \%$ effective rate) were returned in the second-round survey. Because that there is a high response rate requirement for data collected by social networks, those data with a team response rate below $80 \%$ were excluded. ${ }^{33}$ Finally, the study obtained a total of 471 questionnaires from 86 teams, with a valid sample of $73.03 \%$ male and $26.97 \%$ female; the age was mainly between 25 and 45 years old, with an average age of 33 . In terms of education, $3.45 \%$ have doctoral degrees and above, $43.55 \%$ graduate, $43.51 \%$ undergraduate, and $9.49 \%$ high school and below.

\section{Measures}

Team Expertise Location Awareness (Time I)

Team expertise location awareness was calculated by a 4-item survey developed by. ${ }^{20}$ Sample items were "Our team has a good 'map' of each other's' expertise and skills," and "Our team members know what task-related skills and expertise they each possess." Scoring was based on a 7-point Likert scale ranging from 1 (strongly disagree) to 7 (strongly agree). The Alpha Coefficient was 0.88 in the current sample. To verify that whether individual evaluations could be aggregated to the team level, we calculated the inter-rater agreement. Results indicated that the median Rwg (j) is 0.87 , and intraclass correlation ICC $(1)=.36$, ICC $(2)=0.74$; in addition, ANOVA analysis revealed significant differences in team-level means, $F=4.62, p<0.001$. In summary, these evidences support that in all the team surveyed, members shared perceptions regarding team expertise location awareness in their respective teams.

\section{Shared Leadership (Time I)}

We utilized the index of network density to measure the degree of shared leadership. The density metric reflects the total amount of leadership exhibited by team members. ${ }^{34}$ Each team member is asked to rate the other team members regarding the extent to which they rely on that member's leadership. The scale was scored from 1 (very low) to 5 (very high). The density score of shared leadership is obtained by dividing the scores of all members by the total possible scores of the team. $^{25}$

\section{Team Knowledge Integration (Time 2)}

We measured team knowledge integration using a 10-item survey developed by Gardner et al. ${ }^{30}$ Team members were asked to describe the knowledge exchange within their team. The quality of a team's internal communication was measured on ten dimensions such as relevance, timeliness, objectivity, and clarity. Representative items such as “Our team's internal communication is ConciseDigressive" were scored on a 7-point Likert scale ranging from 1 (strongly disagree] to 7 (strongly agree). The consistency reliability coefficient for this measure in this study was 0.88 . To verify that whether individual evaluations could be aggregated to the team level, we calculated the inter-rater agreement. Results indicated that the median Rwg $_{(\mathrm{j})}$ is 0.91 , and intraclass correlation $\operatorname{ICC}(1)=.38$, ICC (2) $=0.76$; in addition, ANOVA analysis revealed significant differences in team-level means, $\mathrm{F}=4.72, p<$ 0.001 . In summary, these evidence support that in all the team surveyed, members shared perceptions regarding team knowledge integration in their respective teams.

\section{Team Improvisation (Time 2)}

Team improvisation was measured by a three-item questionnaire developed by Vera et al. ${ }^{4}$ The team supervisor assessed the team improvisation scale. The Sample items were "During the course of the work, our team is able to respond effectively to unexpected opportunities even though they are not expected". Scoring was based on a 7-point Likert scale ranging from 1 (strongly disagree] to 7 (strongly agree). The reliability coefficient for team improvisation in this study was 0.862 .

\section{Control Variables (Time I)}

We included four control variables to test the hypotheses more rigorously. First, we control for team size because 
team size is thought to affect the difficulty of team communication and knowledge integration. ${ }^{35}$

Second, we control for heterogeneity in team expertise, as heterogeneity in knowledge backgrounds is thought to affect the integration of team knowledge. ${ }^{31}$ This paper uses a three-item scale developed by Tiwana $\&$ Mclean $^{36}$ to test team expertise heterogeneity. Sample items such as "Our team members have a variety of backgrounds and experiences". The scale was scored on a 7-point Likert scale ranging from 1 (strongly disagree) to 7 (strongly agree). The Cronbach's coefficient for this question in this study was 0.91 . In addition, in order to verify that the question items can be aggregated to the team level, team members' evaluations need to have sufficient consistency and reliability. Results indicated that the median value of $\mathrm{Rw}_{\mathrm{g}(\mathrm{j})}$ for team expertise heterogeneity was. 89 , with $\operatorname{ICC}(1)=0.48$ and ICC $(2)=0.80$. Furthermore, ANOVA analysis revealed significant differences in team-level means, $F=4.90, p<$ 0.001 . Therefore, these justify aggregating individual-level team expertise heterogeneity to the team level.

Third, we control for team familiarity because team familiarity is thought to influence the team collaboration process. ${ }^{37}$ Team familiarity was measured by using the social network method; ${ }^{40}$ each member rated their perceived familiarity with each teammate. The study provides each member with a matrix-pattern questionnaire in which the vertical column items are questions concerning familiarities while the horizontal row items are of a complete name list of the team members. Team members were asked to answer the question "How well do you know this team member?" on a 5-point Likert scale from 1 (do not know) to 5 (know a lot). For each team, the average of all team members' scores represents the overall familiarity of the team (this score does not include the members' ratings of themselves).

Finally, we control for the team experimental climate, which is thought to affect the team's ability to improvise. ${ }^{7}$ This paper uses a scale developed by Vera \& Crossan $^{7}$ with four questions, sample questions such as "In teams, mistakes are perceived as a source of learning". Scoring was based on a 7-point Likert scale ranging from 1 (strongly disagree) to 7 (strongly agree). The reliability coefficient of the experimental climate in this study was 0.81 .

\section{Results}

We conducted confirmatory factor analyses (CFA) using Mplus 7.4 to test the discriminant validity of team expertise location awareness, shared leadership, team knowledge integration, and team improvisation. The results show a good model fit $(\chi 2 / \mathrm{df}=2.16$, $\mathrm{df}=225$, RMSEA $=0.05, \mathrm{SRMR}=0.07, \mathrm{CFI}=0.96, \mathrm{TLI}=0.94)$; meanwhile the hypothesized four-factor model show a good model fit degree which significantly outperforms the alternative three-factor model, two-factor as well as one-factor model (see Table 1). Thus, these analyses indicated the discriminant validity of these measures.

We tested all research hypotheses at the team level $(n=$ 86 ), where the key variables in our conceptual model are defined. Table 2 depicts the means, standard deviations, and correlation coefficients for each variable. According to Table 2, it is evident that the team expertise location awareness is positively correlated with the team knowledge integration $(\mathrm{r}=0.24, p<0.05)$. In addition, team knowledge integration is positively correlated with team improvisation $(\mathrm{r}=0.40, p<0.01)$. These correlation patterns provided initial support for our research hypotheses. The inclusion or exclusion of control variables in this analysis did not change the study results.

Hypothesis 1 predicts that the team expertise location awareness would positively predict team knowledge integration. As M1 in Table 3 shows, the regression coefficient of the team expertise location awareness on team knowledge integration is significant $(B=0.17, p<0.01)$. Therefore hypothesis 1 is supported.

Table I Comparison of Measurement Models

\begin{tabular}{|l|c|c|c|c|c|c|}
\hline Model & $\chi \mathbf{2}$ /df & df & $\chi^{\mathbf{2}}$ & RMSEA & CFI & TLI \\
\hline One-factor model & 4.63 & 230 & 1066.11 & 0.21 & 0.54 & 0.49 \\
Two-factor model & 3.57 & 229 & 819.84 & 0.15 & 0.67 & 0.64 \\
Three-factor model & 2.56 & 227 & 490.11 & 0.08 & 0.85 & 0.83 \\
Baseline model & 2.16 & 225 & 485.01 & 0.05 & 0.96 & 0.94 \\
\hline
\end{tabular}

Notes: RMSEA, root mean square error of approximation; SRMR, standardized root mean square residual; CFI, comparative fit index. I) Single factor model: team expertise location awareness + shared leadership + knowledge integration + team improvisation; 2) Two-factor model: team expertise location awareness, shared leadership + knowledge integration, team improvisation; 3) Three-factor model: team expertise location awareness, shared leadership + knowledge integration + team improvisation; 4) Baseline model: team expertise location awareness, shared leadership, knowledge integration, team improvisation. 
Table 2 Means, Standard Deviations, Reliabilities, and Correlations Among Study Variables

\begin{tabular}{|c|c|c|c|c|c|c|c|c|c|c|}
\hline Variables & Mean & SD & $\mathbf{I}$ & 2 & 3 & 4 & 5 & 6 & 7 & 8 \\
\hline I. Team Size & 6.02 & 1.05 & - & & & & & & & \\
\hline 2. Knowledge Heterogeneity & 4.91 & 0.99 & 0.19 & - & & & & & & \\
\hline 3. Team Members' Familiarity & 4.68 & 0.72 & -0.18 & $-0.32^{*}$ & - & & & & & \\
\hline 4. Team Experimental Climate & 4.03 & 0.49 & 0.13 & -0.15 & $0.29 * *$ & - & & & & \\
\hline 5. Team Expertise location Awareness & 5.82 & 1.06 & -0.05 & $-0.25^{*}$ & $0.27^{*}$ & 0.15 & - & & & \\
\hline 6. Shared Leadership & 0.76 & 1.04 & 0.01 & -0.12 & -0.13 & -0.10 & 0.21 & - & & \\
\hline 7. Knowledge Integration & 5.64 & 0.72 & 0.05 & $0.29 * *$ & $-0.22 *$ & -0.01 & $0.24^{*}$ & 0.01 & - & \\
\hline 8. Team Improvisation & 5.29 & 0.63 & -0.01 & $0.38^{* *}$ & -0.19 & 0.01 & -0.07 & -0.10 & $0.40 * *$ & - \\
\hline
\end{tabular}

Notes: $\mathrm{n}=86 .{ }^{*} \mathrm{p}<0.01 .{ }^{*} \mathrm{p}<0.05$.

Hypothesis 2 predicts that the relationship between team expertise location awareness and team knowledge integration is moderated by shared leadership. As M2 in Table 3 shows, the unstandardized regression coefficient for the integration term was positive and significant $(B=$ $0.11, p<0.01)$. In this paper, a simple slope analysis is conducted following the relevant suggestion given by Aiken and West $(1991)^{38}$ (see Figure 2). Figure 2 shows that a significant positive effect of team expertise location awareness on team knowledge integration exists when teams have higher shared leadership ( $1 \mathrm{SD}, B=0.21$, $p<0.001)$. In contrast, when teams have low shared leadership, the relationship between team expertise locations awareness and team knowledge integration is not significant $(-1 \mathrm{SD}, B=0.01, p=0.99)$. Therefore, hypothesis 2 is supported.
Hypothesis 3 predicts that team knowledge integration would positively predict team improvisation. As M3 in Table 3 shows that the regression coefficient of team knowledge integration on team improvisation is significant ( $B=0.24, p<0.01)$. Thus, Hypothesis 3 is supported.

Hypothesis 4 further proposes a moderated mediated model: that is, the indirect effect of team expertise location awareness on team improvisation via team knowledge integration is moderated by shared leadership. To further test hypothesis 4 , we use the bootstrap approach suggested by (Hayes, $2015^{39}$ ). Specifically, we tested this effect by using the bootstrapping approach whereby we constructed bias-corrected confidence intervals based on 5000 random samples with replacement from the full sample. The analysis results are shown in Table 4. Specifically, the indirect effect is more positively significant when shared

Table 3 Regression Results for Knowledge Integration and Team Improvisation

\begin{tabular}{|c|c|c|c|}
\hline \multirow[t]{2}{*}{ Variables } & \multicolumn{2}{|c|}{ Team Knowledge Integration } & \multirow{2}{*}{$\begin{array}{c}\text { Team Decision Making } \\
\text { M3 }\end{array}$} \\
\hline & MI & M2 & \\
\hline \multicolumn{4}{|l|}{ Control variables } \\
\hline Team size & $-0.02(0.07)$ & $-0.03(0.07)$ & $-0.07(0.06)$ \\
\hline Knowledge Heterogeneity & $0.13(0.08)^{*}$ & $0.20(0.07)$ & $0.22(0.07)^{* *}$ \\
\hline Team Members' Familiarity & $-0.16(0.11)$ & $-0.2 \mathrm{I}(0.1 \mathrm{I})$ & $-0.03(0.09)$ \\
\hline Team Experimental Climate & $0.07(0.16)$ & $0.10(0.15)$ & $0.13(0.13)$ \\
\hline \multicolumn{4}{|l|}{ Main effect } \\
\hline Team Expertise location Awareness & $0.17(0.04)^{* *}$ & $0.17(0.04)^{* *}$ & \\
\hline Shared leadership & & $0.33(0.15)^{*}$ & \\
\hline Knowledge integration & & & $0.24(0.08)^{* *}$ \\
\hline \multicolumn{4}{|l|}{ Moderation variables } \\
\hline Expertise location $\times$ Shared & & $0.1 I(0.04)^{* *}$ & \\
\hline \multicolumn{4}{|l|}{ leadership } \\
\hline$R^{2}$ & 0.24 & 0.31 & 0.32 \\
\hline$\Delta R^{2}$ & 0.13 & 0.07 & 0.07 \\
\hline
\end{tabular}

Notes: $\mathrm{N}=86$, Unstandardized regression coefficients are reported. Values in parentheses are standard errors of regression coefficients. Values in bold are relevant to tests of hypotheses. **p $<0.01$. *p $<0.05$ 


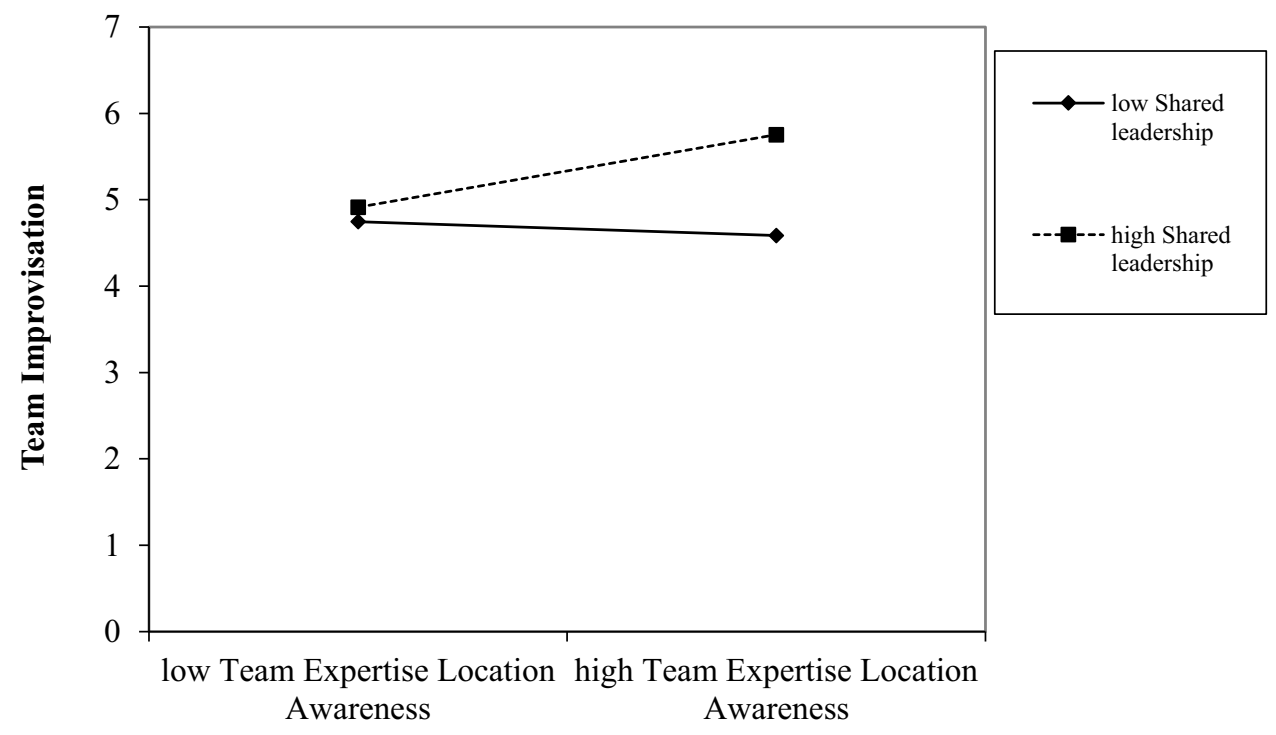

Figure 2 Interactive effect of team expertise location awareness $\times$ shared leadership on team improvisation.

leadership is higher, but it is not significant when shared leadership is low. Thus, hypothesis 4 is supported.

\section{Discussion}

Our overarching purpose in this research is to theorize and test a model to provide novel insight into the premise condition of team improvisation. Drawing from team information processing theory, we examined how teams can achieve high levels of team improvisation by building effective team knowledge integration. Specifically, we explored how team expertise location awareness affects the development of the team knowledge integration and team improvisation capability, and how shared leadership moderates this process. Overall, by testing the moderated mediated model, our study offers a new theoretical perspective to research on team improvisation, highlighting the importance of team knowledge integration in team improvisation.

\section{Theoretical Contributions}

Our research takes a step toward addressing what promotes effective team improvisation. We proposed and found that this relationship is contingent on the team knowledge integration. Previous studies have identified premise conditions such as team information resources and team expertise, ${ }^{4}$ both of which are thought to stimulate team improvisation by providing teams with favorable team knowledge resources. However, team knowledge resources alone do not guarantee effective team outcomes because teams are often unable to integrate and leverage the expertise and resources of their members. ${ }^{41}$ Thus, our first central contribution lies in introducing team knowledge integration as a vital factor that strengthens the team improvisation capability. When encountering a complex environment that changes rapidly, a team must, in its response, continuously integrate its knowledge and information before it can effectively cope with the improvisational demand of the situation. Accordingly, this study provides a microknowledge management perspective for understanding team improvisation and thus offers a new perspective for improvisation research by clarifying the team's integration and utilization of its internal knowledge resources.

Table 4 Moderated Mediating Effect

\begin{tabular}{|l|l|l|l|l|l|}
\hline Mediating Variable & Moderated Variable & Effect & Standard Error & Lower 95\%BC CI & Upper 95\%BC CI \\
\hline Team knowledge Integration & High value & 0.08 & 0.03 & 0.03 & 0.18 \\
& Low value & 0.01 & 0.02 & -0.05 & 0.04 \\
& Difference & 0.07 & 0.01 & 0.08 & 0.14 \\
\hline
\end{tabular}

Note: Cls were calculated using the Monte Carlo method with 5000 repetitions. 
Furthermore, our research revealed that when a team with team expertise location awareness, teams are more likely to achieve team knowledge integration. Although Evans put forward the importance of professional knowledge recognition on team improvisation, the discussion on its mediating mechanism was not deep enough. ${ }^{42}$ This study further expanded its mechanism and proposed the important role of knowledge integration in it. As noted above, simply having experts is not sufficient for effective knowledge resource utilization. Rather, the recognition of each team members' expertise and skills is critical to the team use the full complement of its knowledge resources. We find that team expertise location awareness is not only related to the development of team knowledge integration, but also is particularly valuable when teams need to spontaneously respond to uncertain situations in a novel way.

Third, we also introduce shared leadership as an important team condition that strengthens the relationship between team expertise location awareness and team knowledge integration. Organizational scholars have argued that flexible team interaction patterns promote effective team reactions to unexpected situations. ${ }^{4,42,43}$ Accordingly, shared leadership plays such a tempering role, provides the team with an opportunity to best match members' expertise with the given tasks and eventually promote team knowledge integration.

Finally, most existing team research treats the team as a homogeneous whole rather than a collection of heterogeneous members. ${ }^{44}$ Such a research perspective is based on an oversimplified assumption that individuals in teams are often interchangeable and play an equally important role in driving forward team processes. ${ }^{45}$ However, as Friedrich et $\mathrm{al}^{44}$ summarized, if there are no differences among team members, there is no reason for different individuals to take on different task roles at different times. We focus on team knowledge integration based on the different expertise of team members, do not ignore the importance of each team member who contributes uniquely to the knowledge integration process. This research understands person-to-person differences among team members and provides new and useful ideas for research on team knowledge integration and team improvisation.

\section{Practical Implications}

Our research offers valuable practical insights for both team managers and team members. Indeed, teams face an increasingly volatile and uncertain environment, and teams often need to improvise effectively to achieve their goals. Our study shows that team improvisation depends heavily on the team's ability to dynamically and effectively integrate the team's knowledge resources and information to quickly respond to uncertain team environments. On the one hand, this paper suggests that creating conditions to support dynamic team knowledge integration by enhancing the team expertise location is important for team improvisation. For example, managers can improve team knowledge location awareness in both static and dynamic ways. From a static perspective, managers can create an electronic directory that displays each team member's expertise, background, skills, and past project experience to update members' knowledge of each other's expertise and skills. From a dynamic perspective, organizations can conduct regular meeting reviews to ensure that team members are always aware of each other's expertise and information in real time. These practices can effectively improve the team's cognition of knowledge location and enable the team to integrate knowledge resources more effectively.

On the other hand, managers also need to realize that flexible interaction patterns are important for the integration of knowledge resources, and an organizational environment that is more egalitarian and supportive of shared leadership needs to be built. Only by creating an environment that supports shared leadership can the existing cognitive resources in the team be fully utilized, and can the best of people be truly achieved, and the efficiency and effectiveness of team response be promoted.

\section{Limitations and Future Research}

These contributions should be qualified in light of several limitations. First, although we use the multi-source data collection and adopt objective ratings of team leaders to measure the dependent variable of improvisation, the study still could not eliminate the problem of possible common method bias. Furthermore, since shared leadership often changes over time, ${ }^{25}$ we encourage that future research could consider a combination of experimental and daily data methods for collecting research data so as to better validate the relationships of variables in the design.

Second, what the paper focuses on is the impact of team expertise location awareness as a cognitive resource on team knowledge integration and thus on team improvisation; due to the fact that team expertise perspective more accurately reflects the task characteristics of technical teams in the IT company, the focus of this paper is of 
single-type knowledge resource and expertise location awareness. However, in other types of teams, there might be other kinds of awareness that may be more important than knowledge location awareness, such as interpersonal network relationship awareness that may also play an important role in facilitating the team knowledge integration. Therefore, we encourage researchers to consider the effects of other cognition resources on team knowledge integration in the future.

Finally, this research considers the boundary conditions for the play of team expertise location from team member's interaction perspective, ie, shared leadership perspective. However, other factors such as team affection, including shared team identity, may also promote better team recognition. Therefore, future researchers are encouraged to explore the moderating role between team expertise location and improvisation from other psychological perspectives.

\section{Conclusion}

Our research identifies team knowledge integration as an important premise condition for team improvisation. The results suggest that team expertise location awareness positively affects team improvisation through team knowledge integration; team knowledge integration is strengthened when teams with high-level shared leadership. By testing the moderated mediated model, our study helps understanding why some teams can improvise better than others and provides empirical and practical insights into how team knowledge integration can drive effective team improvisation. By explicating this phenomenon, we suggest that scholarly attention should not merely focus on optimizing team knowledge resources for effective team improvisation capability, but also considers how to use its knowledge resources well during the team reaction process.

\section{Data Sharing Statement}

The raw data supporting the conclusions of this article will be made available by the first author, without undue reservation.

\section{Institutional Review Board Statement}

The study was conducted according to the guidelines of the Declaration of Helsinki, and approved by the Institutional Review Board of Zhejiang Gongshang University \& Wenzhou University.

\section{Informed Consent Statement}

Informed consent was obtained from all subjects involved in the study.

\section{Funding}

This work was supported by National Natural Science Foundation of China (No. 72074195) and Project of Philosophy and Social Science Research, Ministry of Education, China (No. 19YJA630092). It was also supported by the project of "Executives' Dynamic Relationship Network, System Differences, and Chinese Enterprises' Internationalization Strategy: Internal Mechanism and Empirical Test" (Grant No.: 21NDJC144YB) (2021 Philosophy and Social Science Project of Zhejiang Province) and the project of "Multidimensional evaluation paradigm of scientific literature and evaluation System of scientific and technological talents under the background of 'Breaking four principles and Establishing new Standards" " (Grant No.: 21wsk169) (Zhejiang Soft Science Research Plan in 2022).

\section{Disclosure}

The authors declare no conflict of interest.

\section{References}

1. Greer LL, de Jong BA, Schouten ME, Dannals JE. Why and when hierarchy impacts team effectiveness: a meta-analytic integration. J Appl Psychol. 2018;103(6):591-613. doi:10.1037/ap10000291

2. Gino F, Argote L, Miron-Spektor E, Todorova G. First, get your feet wet: the effects of learning from direct and indirect experience on team creativity. Organ Behav Hum Decis Process. 2010;111(2):102-115. doi:10.1016/j.obhdp.2009.11.002

3. Wang Z, Ren S, Chadee D, Liu M, Cai S. Team reflexivity and employee innovative behavior: the mediating role of knowledge sharing and moderating role of leadership. J Knowl Manag. 2021;25 (6):1619-1639. doi:10.1108/JKM-09-2020-0683

4. Vera D, Nemanich L, Vélez-Castrillón S, Werner S. Knowledge-Based and Contextual Factors Associated with R\&D Teams' Improvisation Capability. $J$ Manage. 2016;42(7):1874-1903. doi:10.1177/ 0149206314530168

5. Sway P. The "Third Hand": IT-enabled competitive advantage in $\mathrm{T}$ urbulence through improvisational capabilities. Inf Sys Res. 2010;21(3):443-471. doi:10.1287/isre.1100.0280

6. Hadida AL, Tarvainen W, Rose J. Organizational improvisation: a consolidating review and framework. Int J Manag Rev. 2015;17 (4):437-459. doi:10.1111/ijmr.12047

7. Vera D, Crossan M. Improvisation and Innovative Performance in Teams. Organ Sci. 2005;16(3):203-224. doi:10.1287/orsc. 1050.0126

8. Banin AY, Boso N, Hultman M, Souchon AL, Hughes P, Nemkova E. Salesperson improvisation: antecedents, performance outcomes, and boundary conditions. Ind Marketing Manag. 2016;59:120-130. doi:10.1016/j.indmarman.2016.02.007

9. Magni M, Proserpio L, Hoegl M, Provera B. The role of team behavioral integration and cohesion in shaping individual improvisation. Res Policy. 2009;38(6):1044-1053. doi:10.1016/j.respol.2009.03.004 
10. Aime, Federico, et al. The riddle of heterarchy: Power transitions in cross-functional teams. Academy of Management Journal. 2014;57 (2):327-352. doi:10.5465/amj.2011.0756

11. Woolley AW, Gerbasi ME, Chabris CF, Kosslyn SM, Hackman JR. Bringing in the experts: how team composition and collaborative planning jointly shape analytic effectiveness. Small Group Res. 2009;39(3):352-371. doi:10.1177/1046496408317792

12. Tushman ML, Nadler DA. Information processing as an integrating concept in organizational design. Acad Manag Rev. 1978;3 (3):613-624. doi:10.5465/amr.1978.4305791

13. Scholten L, Knippenberg D. Motivated information processing and group decision-making: effects of process accountability on information processing and decision quality. J Exp Soc Psychol. 2007;43 (4):539-552. doi:10.1016/j.jesp.2006.05.010

14. Bunderson JS. Recognizing and utilizing expertise in work groups: a status characteristics perspective. Adm Sci Q. 2003;48(4):557-591. doi: $10.2307 / 3556637$

15. Stasser G, Stewart DD, Wittenbaum GM. Expert roles and information exchange during discussion: the importance of knowing who knows what. J Exp Soc Psychol. 1995;31(3):244-265. doi:10.1006/ jesp. 1995.1012

16. Kanawattanachai P, Yoo Y. The impact of knowledge coordination on virtual team performance over time. MIS Quarterly. 2007;31 (4):783-808. doi:10.2307/25148820

17. Lewis K, Herndon B. Transactive memory systems: current issues and future research directions. Organ Sci. 2011;22(5):1254-1265. doi:10.1287/orsc. 1110.0647

18. Krylova KO, Vera D, Crossan M. Knowledge transfer in knowledge-intensive organizations: the crucial role of improvisation in transferring and protecting knowledge. J Knowl Manag. 2016;20 (5):1045-1064. doi:10.1108/jkm-10-2015-0385

19. Ali A, Wang H, Johnson RE. Empirical analysis of shared leadership promotion and team creativity: an adaptive leadership perspective J Organ Behav. 2020;41(5):405-423. doi:10.1002/job.2437

20. Faraj S, Sproull L. Coordinating expertise in software development teams. Manage Sci. 2000;46(12):1554-1568. doi:10.1287/ mnsc.46.12.1554.12072

21. Gajendran RS, Joshi A. Innovation in globally distributed teams: the role of LMX, communication frequency, and member influence on team decisions. J Appl Psychol. 2012;97(6):1252-1261. doi:10.1037/ a0028958

22. Baumann MR, Bonner BL. The effects of variability and expectations on utilization of member expertise and group performance. Organ Behav Hum Decis Process. 2004;93(2):89-101. doi:10.1016/j. obhdp.2003.12.004

23. Berman SL, Down J, Hill CW. Tacit knowledge as a source of competitive advantage in the National Basketball Association. Acad Manag J. 2002;45(1):13-31. doi:10.5465/3069282

24. Okhuysen GA, Bechky BA. Coordination in organizations: an integrative perspective. Acad Manag Ann. 2009;3(1):463-502. doi:10.1080/19416520903047533

25. Mathieu JE, Kukenberger MR, D’Innocenzo L, Reilly G. Modeling reciprocal team cohesion-performance relationships, as impacted by shared leadership and members' competence. J Appl Psychol. 2015;100(3):713-734. doi:10.1037/a0038898

26. Nicolaides VC, LaPort KA, Chen TR, et al. The shared leadership of teams: a meta-analysis of proximal, distal, and moderating relationships. Leadersh Q. 2014;25(5):923-942. doi:10.1016/j. leaqua.2014.06.006

27. Wang D, Waldman DA, Zhang Z. A meta-analysis of shared leadership and team effectiveness. J Appl Psychol. 2014;99(2):181-198. doi: $10.1037 / \mathrm{a} 0034531$
28. Pearce, Craig L., \& Jay A. Conger (Eds.) (2003). Shared Leadership: Reframing the Hows and Whys Leadership. Thousand Oaks, CA: Sage Publications.

29. D'Innocenzo L, Mathieu JE, Kukenberger MR. A meta-analysis of different forms of shared leadership-team performance relations. J Manage. 2016;42(7):1964-1991. doi:10.1177/0149206314525205

30. Gardner HK, Gino F, Staats BR. Dynamically integrating knowledge in teams transforming resources into performance. Acad Manag Ann. 2012;55(4):998-1022. doi:10.5465/amj.2010.0604

31. Lv J, Zhang G. The mechanisms of knowledge heterogeneity on creativity of knowledge teams: an interactive cognition perspective. Acta Psychol Sinica. 2015;47(4):533. doi:10.3724/sp. j.1041.2015.00533

32. Podsakoff PM, MacKenzie SB, Podsakoff NP. Sources of method bias in social science research and recommendations on how to control it. Ann Rev Psychol. 2012;63(1):539-569. doi:10.1146/ annurev-psych-120710-100452

33. Chiu CC, Owens BP, Tesluk PE. Initiating and utilizing shared leadership in teams: the role of leader humility, team proactive personality, and team performance capability. $J$ Appl Psychol. 2016;101(12):1705-1720. doi:10.1037/ap10000159

34. Carson JB, Tesluk PE, Marrone JA. Shared leadership in teams- an investigation of antecedent conditions and performance. Acad Manag Ann. 2007;50(5):1217-1234. doi:10.5465/amj.2007.20159921

35. Hackman JR, Wageman R. A theory of team coaching. Acad Manag Rev. 2005;30(2):269-287. doi:10.5465/amr.2005.16387885

36. Tiwana A, Mclean ER. Expertise Integration and Creativity in Information Systems Development. J Manag Inf Sys. 2005;22 (1):13-43. doi:10.1080/07421222.2003.11045836

37. Avgerinos E, Fragkos I, Huang Y. Team familiarity in cardiac surgery operations: the effects of hierarchy and failure on team productivity. Human Relations. 2019;73(9):1278-1307. doi:10.1177/ 0018726719857122

38. Aiken, L. S., \& West, S. G. (1991). Multiple regression: Testing and interpreting interactions. Newbury Park, CA: Sage.

39. Hayes, Andrew F. An index and test of linear moderated mediation. Multivariate behavioral research. 2015;50(1):1-22. doi:10.1080/ 00273171.2014 .962683

40. Lewis K. Knowledge and performance in knowledge-worker teams: a longitudinal study of transactive memory systems. Manage Sci. 2004;50(11):1519-1533. doi:10.1287/mnsc.1040.0257

41. Ilgen DR, Hollenbeck JR, Johnson M, Jundt D. Teams in organizations: from input-process-output models to IMOI models. Annu Rev Psychol. 2005;56:517-543. doi:10.1146/annurev. psych.56.091103.070250

42. Evans KO. Mining for Solutions How Expertise Distribution and Influence Structures Impact Team Improvisation. Washington University in St. Louis; 2016:552.

43. Abrantes ACM, Passos AM, Cunha MP, Santos CM. Bringing team improvisation to team adaptation: the combined role of shared temporal cognitions and team learning behaviors fostering team performance. J Bus Res. 2018;84:59-71. doi:10.1016/j. jbusres.2017.11.005

44. Friedrich TL, Vessey WB, Schuelke MJ, Ruark GA, Mumford MD. A framework for understanding collective leadership: the selective utilization of leader and team expertise within networks. Leadersh $Q$. 2009;20(6):933-958. doi:10.1016/j.leaqua.2009.09.008

45. Li N, Zhao HH, Walter S, Zhang X-A, Yu J. Achieving more with less: extra milers behavioral influences in teams. J Appl Psychol. 2015;100(4):1025-1039. doi:10.1037/apl0000010 


\section{Publish your work in this journal}

Psychology Research and Behavior Management is an international, peer-reviewed, open access journal focusing on the science of psychology and its application in behavior management to develop improved outcomes in the clinical, educational, sports and business arenas. Specific topics covered in the journal include: Neuroscience, memory and decision making; Behavior modification and management; Clinical applications; Business and sports performance management; Social and developmental studies; Animal studies. The manuscript management system is completely online and includes a very quick and fair peer-review system, which is all easy to use. Visit http://www. dovepress.com/testimonials.php to read real quotes from published authors. 